\title{
Sodium/Potassium-Transporting ATPase Subunit Alpha-1
}

National Cancer Institute

\section{Source}

National Cancer Institute. Sodium/Potassium-Transporting ATPase Subunit A/pha-1. NCI

Thesaurus. Code C113764.

Sodium/potassium-transporting ATPase subunit alpha-1 (1023 aa, 113 kDa) is encoded by the human ATP1A1 gene. This protein is involved in both cation transport and ATP hydrolysis. 